\title{
A pair of orthologs of a leucine-rich repeat receptor kinase-like disease resistance gene family regulates rice response to raised temperature
}

\author{
Haitao Zhang, Yinglong Cao, Jing Zhao, Xianghua Li, Jinghua Xiao and Shiping Wang*
}

\begin{abstract}
Background: Rice Xa3/Xa26 disease-resistance gene encodes a leucine-rich repeat (LRR) receptor kinase-type protein against Xanthomonas oryzae pv. oryzae $\left(X_{0 O}\right)$ and belongs to a multigene family. However, the functions of most genes in this family are unknown.

Results: Here we report that two orthologs of this family, the NRKe from rice variety Nipponbare and 9RKe from variety 93-11 at the RKe locus, have similar functions although they encode different proteins. This pair of orthologs could not mediate resistance to $X_{0}$, but they were transcriptionally induced by raised temperature. Transcriptional activation of NRKe or 9RKe resulted in the formation of temperature-sensitive lesion mimics, which were spots of dead cells associated with accumulation of superoxides, in different organs of the transgenic plants. These plants were more sensitive to high temperature shock than wild-type controls. Transgenic plants carrying a chimeric protein consisting of the LRR domain of NRKe and the kinase domain of Xa3/Xa26 developed the same lesion mimics as the NRKe-transgenic plants, whereas transgenic plants carrying another chimeric protein consisting of the LRR domain of Xa3/Xa26 and the kinase domain of NRKe were free of lesion mimic. All the transgenic plants carrying a chimeric protein were susceptible to Xoo.

Conclusion: These results suggest that the RKe locus is involved in rice response to raised temperature. The LRR domain of RKe protein appears to be important to sense increased temperature. The RKe-involved temperaturerelated pathway and Xa3/Xa26-mediated disease-resistance pathway may partially overlap.
\end{abstract}

\section{Background}

Disease resistance $(R)$ genes that mediate race-specific resistance are important for plants in defending themselves from various pathogen attacks. Currently, many $R$ genes have been characterized and most of them encode proteins sharing common features. The most prevalent domain of characterized $R$ proteins is the leucine-rich repeat (LRR), which is the major determinant of pathogen recognition [1]. A relatively large number of LRRcontaining $\mathrm{R}$ proteins belong to the nucleotide-binding site-LRR class [2]; most of the characterized $R$ genes against Magnaporthe oryzae, which causes rice fungal blast, belong to this class [3]. The second class is the LRR receptor-like $\mathrm{R}$ proteins that consist of an extracellular

\footnotetext{
* Correspondence: swang@mail.hzau.edu.cn National Key Laboratory of Crop Genetic Improvement, National Center of Plant Gene Research (Wuhan), Huazhong Agricultural University, Wuhan 430070, China
}

(c) 2011 Zhang et al; licensee BioMed Central Ltd. This is an Open Access article distributed under the terms of the Creative Commons Attribution License (http://creativecommons.org/licenses/by/2.0), which permits unrestricted use, distribution, and reproduction in any medium, provided the original work is properly cited.
LRR domain and a transmembrane motif [4]; no rice $R$ gene of this class has been characterized so far. The last class includes the LRR receptor kinase-like R proteins, which are only identified in rice so far [5,6]. Both LRR and kinase domain are common structures in many signaling pathways. Plants have a large number of LRR receptor kinase-like proteins [7]. All the LRR receptor kinase-like proteins contain a transmembrane motif, which departs the LRR domain to stay outside of the plasma [7]. Thus, as cell surface receptors, the LRR receptor kinase-like proteins are thought to recognize special extracellular ligands via the LRR domain and initiate the downstream signaling through the intracellular kinase domain.

Rice $R$ gene $\mathrm{Xa3} / \mathrm{Xa} 26$ confers race-specific resistance to Xanthomonas oryzae pv. oryzae (Xoo) that causes bacterial blight, one of the most devastating diseases of rice worldwide and it encodes a LRR receptor kinase-like 
protein [6]. Xa3/Xa26 belongs to a tandem clustered multiple gene family in the long arm of rice chromosome $11[8,9]$. Point mutations with positive selection were a major force of the evolution of this family [9]. Both paralogs (in the same rice variety) and orthologs (in different rice varieties) of this family have similar tissue-specific expression patterns, suggesting that they may have similar functions $[10,11]$. In addition, at least some paralogs of this family have dosage effects, in which their disease resistance functions are associated with their transcript amounts [12,13]. The expression of Xa3/Xa26 is developmentally regulated. It has a lower level of expression at the early developmental stage, but a higher level of expression at the late developmental stage, which results in rice plants carrying $\mathrm{Xa3} / \mathrm{Xa26}$ being susceptible to some Xoo strains at the seedling stage but showing enhanced resistance to the same Xoo strains at the adult stages [12]. Rice plants constitutively overexpressing $\mathrm{Xa3} / \mathrm{Xa26}$ have an enlarged resistance spectrum, an increased level of resistance, and a whole growth-stage resistance without influencing their morphologies and agronomic performance $[12,14]$. In addition, the ortholog alleles at $\mathrm{Xa3/Xa26}$ locus confer a durable resistance to $X o o$ [15]. Another paralog of the $X a 3 / X a 26$ family, the $M R K a$, could not mediate resistance to Xoo when regulated by its native promoter, but MRKa could confer partial resistance to $X o o$ when regulated by a strong constitutive promoter [13].

To ascertain the functions of other paralogs of the Xa3/ Xa26 family, we constitutively expressed two orthologs of this family, NRKe and 9RKe, from two rice varieties, at the $R K e$ locus. This pair of orthologs cannot mediate resistance to Xoo as do their paralogs $\mathrm{Xa3} / \mathrm{Xa26}$ and $M R K a$ in the present experimental condition. However, they are involved in rice response to raised temperature.

\section{Methods}

\section{Plasmid construction and rice transformation}

To overexpress 9RKe and NRKe in rice, these two genes were amplified using polymerase chain reaction (PCR) primers NRKe-F and NRKe-R (Additional file 1, Table S1) and genomic DNA from indica rice variety 93-11 (Oryza sativa L. ssp. indica) and bacterial artificial clone (BAC) OSJNBa0004O15 from japonica variety Nipponbare (O. sativa L. ssp. japonica) as template, respectively. The PCR products were digested with $\mathrm{BamHI}$ and ligated into the transformation vector pU1301, which contained a maize ubiquitin gene promoter to drive the inserted gene [12].

To study the function of different domains of NRKe, two mutations of NRKe were generated. The kinase domain-deleted NRKe, the $N R K e-\Delta K$, was created by PCR amplification using primers NRKe-F and B+E-3 and the LRR-transmembrane motif-deleted NRKe, the NRKe-
$K$, was created by $\mathrm{PCR}$ amplification using primers RKe-6F and NRKe-R (Additional file 1, Table S1). Both truncated genes were amplified using Nipponbare BAC OSJNBa0004O15 as template. The PCR products then were ligated into pU1301 under the regulation of maize ubiquitin gene promoter. Two chimeric genes, $\mathrm{Be} 1$ and $B e 2$, which consist of different fragments of NRKe and $\mathrm{Xa3} / \mathrm{Xa26}$, were amplified by overlap extension PCR [16]. PCR primers MKb-F, B+E-1, B+E-2, and NRKe-R were used for construction of $\mathrm{Bel}$ and primers NRKe-F, B+E3, $\mathrm{B}+\mathrm{E}-4$, and $\mathrm{MKb}-\mathrm{R}$ were used for construction of $\mathrm{Be} 2$ (Additional file 1, Table S1). Both chimeric genes were amplified using BAC 3H8, which harbors $\mathrm{Xa3} / \mathrm{Xa26}$, from rice variety Minghui 63 (O. sativa L. ssp. indica) and Nipponbare BAC OSJNBa0004O15 as templates. The PCR products were ligated into pU1301 under the regulation of maize ubiquitin gene promoter.

All the constructs were respectively transferred into Agrobacterium tumefaciens strain EHA105 by electroporation. Rice transformation was performed by the Agrobacterium-mediated method using calli generated from mature embryos of rice variety Mudanjiang 8 (O. sativa L. ssp. japonica) [17].

\section{Pathogen inoculation}

Plants were inoculated with Philippine Xoo strains PXO61, PXO86, PXO71, and PXO99 by the leaf-clipping method at the booting (panicle development) stage [18]. Disease was scored by measuring the percentage disease area (lesion length/leaf length) at 2 weeks after inoculation.

\section{Temperature treatment}

Rice plants grown in a greenhouse at approximately $24^{\circ} \mathrm{C}$ were transferred to growth chambers for temperature experiments at the tillering stage. The growth chamber conditions were controlled as 70\% humidity, 14-h light, and 10 -h dark at either $24^{\circ} \mathrm{C}$ or $35^{\circ} \mathrm{C}$. For heat shock, transgenic and wild-type plants were grown in the same pots and transferred to a $42^{\circ} \mathrm{C}$ growth chamber for $32 \mathrm{~h}$ (until almost all the leaves of one group in the pot became completely rolled and some leaves died). The plants were then recovered by maintaining them at room temperature for $3 \mathrm{~d}$ and phenotypes were recorded.

\section{Gene expression analyses}

RNA gel blot analysis was performed as described previously [19]. A 343-bp probe for both NRKe and 9RKe, digested using BamHI and SacI from the PCR product amplified using primers NRKe-F and NRKe-R (Additional file 1, Table S1), was used for hybridization. Quantitative reverse transcription-PCR (qRT-PCR) was performed using gene-specific primers (Additional file 1, Table S1), as described previously [20]. The expression of actin gene was first used to standardize the RNA sample 
for each qRT-PCR. For each gene, qRT-PCR assays were repeated at least twice, with each repetition having three replicates. Only the results in one repetition were presented when similar results were obtained in repeated experiments. The level of expression relative to control was presented.

\section{Promoter sequence analysis}

The putative cis-acting elements in the promoter regions of NRKe and 9RKe were predicted at PlantCARE http:// bioinformatics.psb.ugent.be/webtools/plantcare/html/ and PLACE http://www.dna.affrc.go.jp/PLACE/ databases.

\section{Results}

Overexpression of RKe resulted in the formation of lesion mimics in rice plants

The paralog $R K e$ of the $R$ gene $X a 3 / X a 26$ family only exists in some rice varieties [9]. The $R K e$ genes in rice varieties 93-11 and Nipponbare, named 9RKe [GenBank accession number: JN176871] and NRKe [JN176870], respectively, had $99.6 \%$ sequence identity. Both genes putatively encode proteins consisting of 1097 amino acids but with a five-residue difference (Figure 1a).

At least some paralogs of the $X a 3 / \mathrm{Xa} 26$ family have dosage effects in rice-bacterium interactions $[12,13]$. To ascertain whether NRKe and 9RKe also functioned in rice disease resistance, we constitutively overexpressed them in susceptible rice variety Mudanjiang 8 , in which $R K e$ was not detected. Twenty-two and 17 independent transformants transformed with NRKe and 9RKe and named NRKe-oe and 9RKe-oe were obtained, respectively. Some of the $\mathrm{T}_{0}$ plants showed overexpression of NRKe or 9RKe (Additional file 1, Figure S1). All the $\mathrm{T}_{0}$ plants were inoculated with Xoo strain PXO61 at the booting stage and all the plants were susceptible as the wild-type Mudanjiang 8. After all the $\mathrm{T}_{0}$ plants were cut at about $12 \mathrm{~cm}$ above ground level after seeds had been harvested, the regenerated plants from the stubs were inoculated with other Xoo strains PXO86, PXO71, or PXO99. The transgenic plants were susceptible to these Xoo strains as the wild-type plants. Two independent $T_{1}$ families generated from two $\mathrm{T}_{0}$ plants that overexpressed NRKe were inoculated with Xoo strain PXO61 for further analysis, but both families showed no difference from wild-type Mudanjiang 8. These results suggest that NRKe and 9RKe may not have roles in rice-Xoo interaction.

Interestingly, 11 of the 22 NRKe-oe $\mathrm{T}_{0}$ plants and 12 of the 17 9RKe-oe $\mathrm{T}_{0}$ plants developed similar brown lesion mimics (i.e., spots that resemble infection) on leaf blades, leaf sheaths, and peduncles of panicles at the adult stage (Figure 1b). The lesion mimics could appear at any growth stage as small ones and developed to large ones during plant growth, but were restricted to an area around the initiation point. The lesion also could be formed spontaneously when the transgenic plants were grown in a sterilized tube or flask (Additional file 1, Figure S2). These results suggest that the formation of lesions is not related to pathogen infection.

Staining the leaves of the transgenic plants with visible lesion mimics using trypan blue, an indicator of dead cells [21], showed dark blue-stained spots at the sites around lesion mimics; such dark blue spots were not observed in the leaves of wild-type plants (Figure 1c). Autofluorescence, an indicator of phenolic compounds produced during cell death of hypersensitive response [22], was also detected at the sites of lesion mimics in the leaves of transgenic plants under the microscope after ultraviolet stimulation; no autofluorescence was detected in the leaves of wild-type plants (Figure 1c). The leaves with visible lesion mimics were also stained with 3,3-diaminobenzidin and nitro blue tetrazolium, the indicators of $\mathrm{H}_{2} \mathrm{O}_{2}$ and superoxides, respectively [23]. The leaves of the transgenic plants showed markedly increased dark staining at the sites of lesion mimics as compared to the leaves of wildtype plants after both 3,3-diaminobenzidin and nitro blue tetrazolium staining, indicating the accumulation of $\mathrm{H}_{2} \mathrm{O}_{2}$ and superoxides in the transgenic plants (Figure 1c). These results suggest that the lesions of the NRKe-oe and 9RKe-oe plants were related to cell death, which may be associated with the accumulation of superoxides including $\mathrm{H}_{2} \mathrm{O}_{2}$. Because the NRKe-oe and 9RKe-oe plants developed similar lesion mimics, only the NRKe-oe plants were used for some of the further analyses.

To determine whether the development of lesion mimics was due to overexpressed NRKe, two $\mathrm{T}_{1}$ families (NRKe-oe6 and NRKe-oe15) derived from two of the $\mathrm{T}_{0}$ plants that developed lesion mimics were further examined for their phenotypes and the existence of NRKe-oe construct. The development of lesion mimics on the leaves cosegregated with the existence of NRKe in the two families (Figure 1d). These results suggest that overexpressing NRKe caused the formation of spontaneous lesion mimics in rice.

\section{Formation of lesion mimics in NRKe-oe plants was temperature sensitive}

Lesion mimic formation is a complex physiologic reaction in plants and may be caused by many biotic or abiotic factors. Because the NRKe-oe plants appeared not to be involved in rice-Xoo interaction, the formation of lesion mimics in these plants may be influenced by other environmental factors. Actually, two batches of NRKe-oe plants were generated in our experiments. The first batch of transgenic plants was planted in the field in early summer and marked lesion mimics were observed on their leaves when the plants grew to the booting stage during the summer. The second batch of transgenic plants was generated about $50 \mathrm{~d}$ later and was planted in the field in 


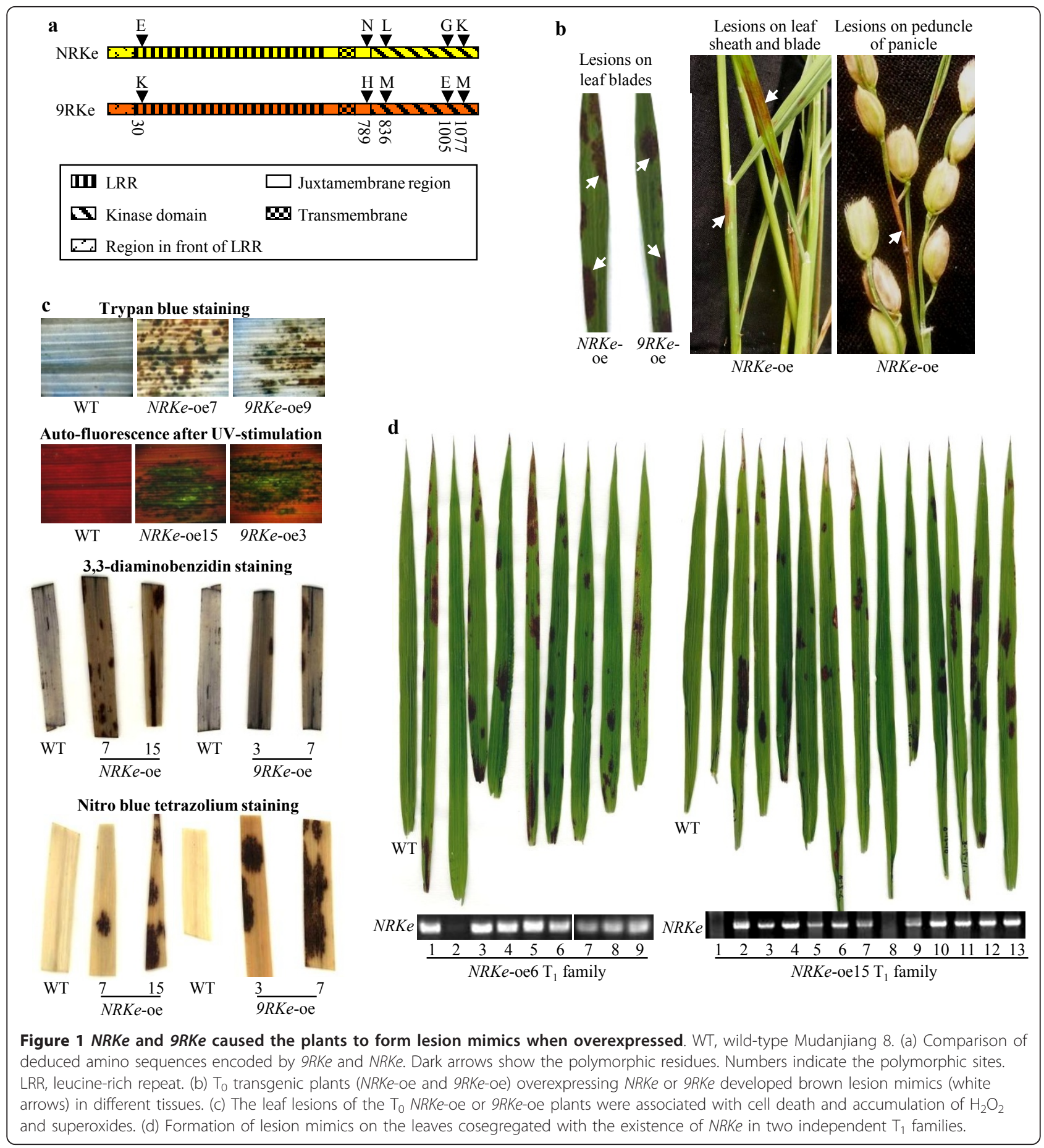

late summer. When the second batch of plants grew to the booting stage in the autumn, no obvious lesion mimic was observed in these plants. But after the second batch of plants was transferred to a greenhouse that had a higher temperature than the field condition, marked lesion mimics were formed on their leaves. These observations led us to infer that temperature may influence the formation of lesion mimics.
To test this inference, two identical sets of plants, including NRKe-oe and 9RKe-oe plants, wild-type Mudanjiang 8 , and rice varieties Nipponbare (the donor of $N R K e$ ) and 93-11 (the donor of 9RKe) in each set, were grown in different temperatures at the tillering stage. The two sets of plants were first grown at $24^{\circ} \mathrm{C}$ and $35^{\circ} \mathrm{C}$, respectively, for 10 to $18 \mathrm{~d}$. All the plants grown at $24^{\circ} \mathrm{C}$ were free of lesion mimics. For the set of plants 
grown at $35^{\circ} \mathrm{C}$, the $N R K e$-oe and $9 R K e$-oe plants formed marked lesion mimics on their leaves at 10 and $18 \mathrm{~d}$ after being at $35^{\circ} \mathrm{C}$, respectively, whereas the control Mudanjiang 8, Nipponbare, and 93-11 were free of lesions (Figure 2a). When the $24^{\circ} \mathrm{C}$-pretreated NRKe-oe and control plants were transferred to $35^{\circ} \mathrm{C}$, the transgenic plants but not control plants developed lesion mimics on their leaves even at $3 \mathrm{~d}$ after growing in $35^{\circ} \mathrm{C}$ (Figure $2 \mathrm{~b}$ ). These results suggest that higher temperature may induce the formation of lesion mimics in NRKe-oe and 9RKe-oe plants.

Temperature influenced the expression of NRKe and 9RKe To ascertain whether temperature transcriptionally influenced NRKe and 9RKe, we comparatively analyzed the expression of $N R K e$ and $9 R K e$ in wild-type plants at different temperatures. At $35^{\circ} \mathrm{C}$, the expression of NRKe and $9 R K e$ was markedly induced at $12 \mathrm{~h}$ after temperature treatment and then returned to the basal level of expression at $1 \mathrm{~d}$ after temperature treatment; the transcripts increased approximately 2 - to 2.5 -fold at $12 \mathrm{~h}$ after $35^{\circ} \mathrm{C}$ treatment compared to untreated control plants (Figure 3a). Raising the temperature to $42^{\circ} \mathrm{C}$ further increased the expression of NRKe and 9RKe; the transcripts of NRKe and 9RKe increased approximately 30- and 7-fold at $12 \mathrm{~h}$ after treatment, respectively. However, NRKe and 9RKe expression was only slightly induced when the plants were kept at $24^{\circ} \mathrm{C}$.

The promoter regions (approximately $2 \mathrm{~kb}$ upstream of translation start codon ATG) of NRKe and 9RKe had 98\% sequence identity. The two sequences were analyzed for putative cis-acting elements involved in heat stress response by searching different databases. The most canonical heat shock element (HSE) consists of a repeated core sequence of nGAAn ('n' indicating any nucleotide) in alternate orientation [24]. In the promoter regions of NRKe and 9RKe, two imperfect nGAAn repeats were identified. The first nGAAn repeat was 'acTCaaTTCagGAAt' for NKRe and 'acTCaaTTCagGAta' for $9 R K e$, and the second was 'aGAAtgGAgaacTCcatAAatcTCa' for both genes (Figure 3b; Additional file 1, Figure S3). The promoter regions of the two genes also harbored another putative HSE, which was complementary to the HSE 'AAAAAATTTC' of Brassica oleracea

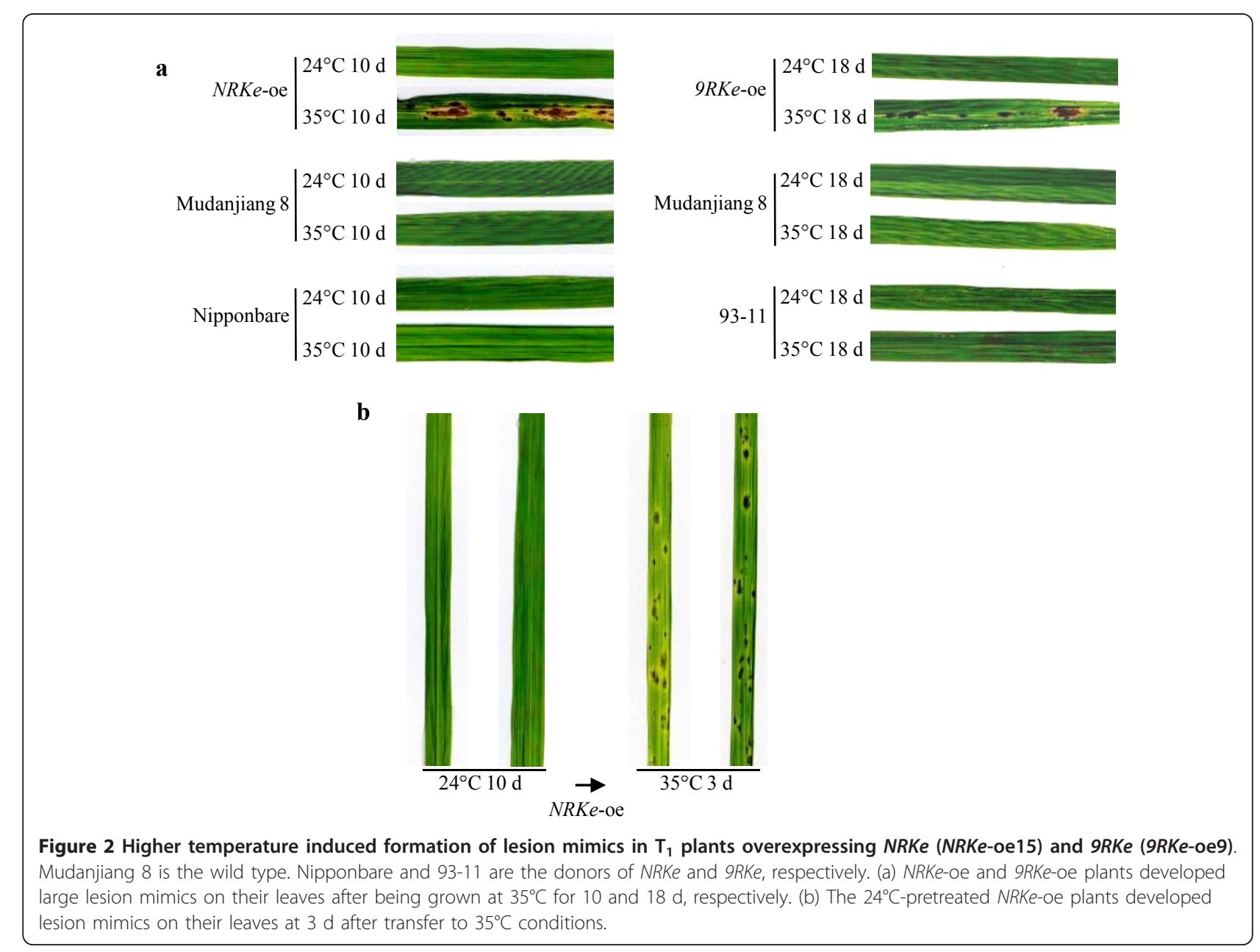



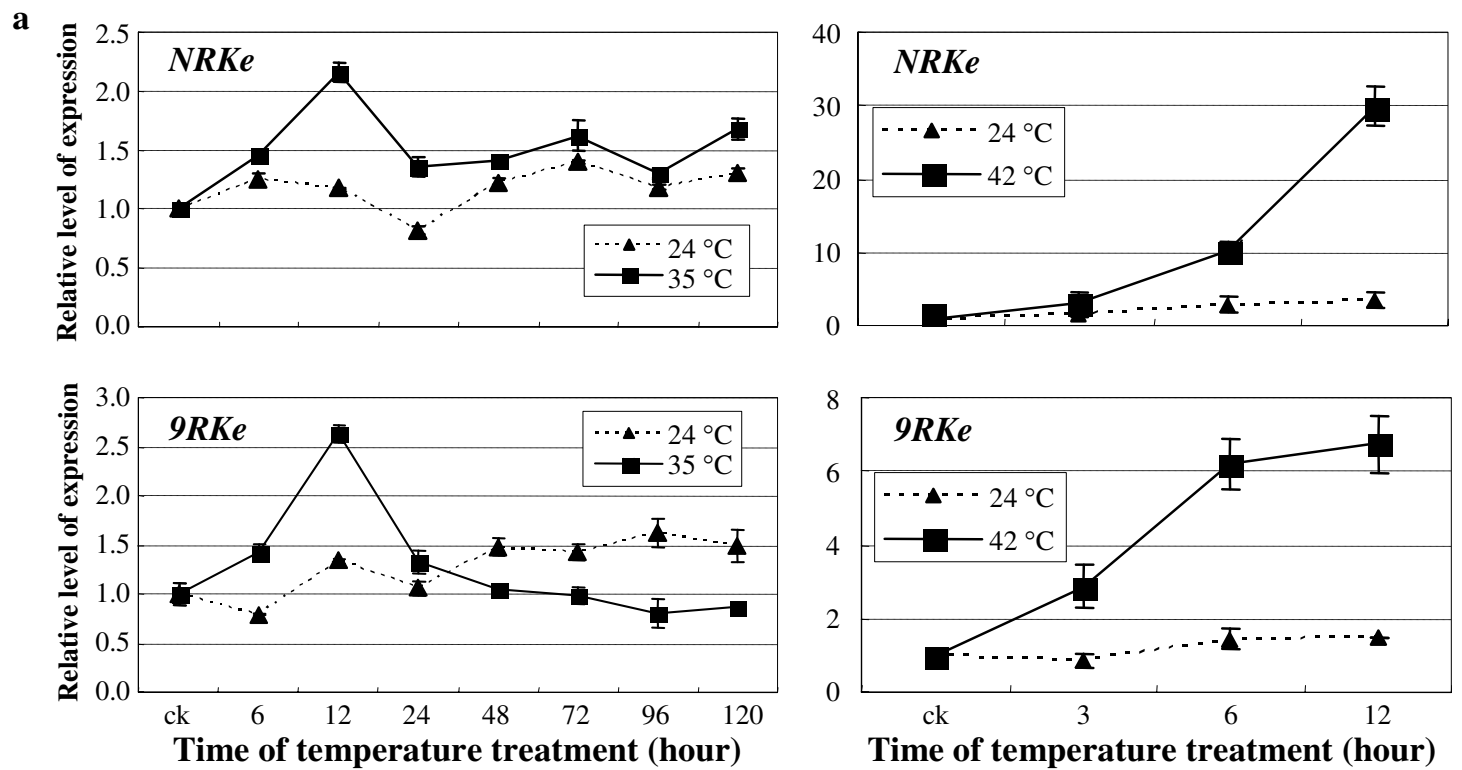

Time of temperature treatment (hour)
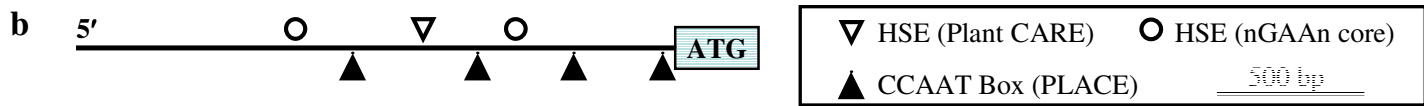

Figure 3 Expression of NRKe and 9RKe was induced after higher temperature treatment. (a) Expression patterns of NRKe in rice variety Nipponbare and 9RKe in rice variety 93-11 in different temperatures. ck, untreated control. (b) Putative heat-responsive cis-acting elements in the promoter regions of NRKe and 9RKe. HSE (nGAAn core), heat shock element consisting of repeated core sequence of nGAAn in alternate orientation; HSE (PlantCARE), heat shock element found in PlantCARE database; CCAAT box (Place), CCAAT box found in PLACE database.

(Figure 3b; Additional file 1, Figure S3). Four CCAAT boxes were also identified in the promoter regions (Figure 3b; Additional file 1, Figure S3). The CCAAT box has been reported to act cooperatively with HSEs to increase promoter activity [25]. The occurrence of putative heat-responsive cis-elements and heat-induced expression suggest that NRKe and 9RKe may function in early response to increased temperature.

\section{Activation of NRKe and 9RKe expression influenced rice response to increased temperature}

To examine the inference that NRKe and 9RKe are involved in rice response to increased temperature, NRKeoe or $9 R K e$-oe plants and their wild-type plants were treated at $42^{\circ} \mathrm{C}$. After treatment, the NRKe-oe and $9 R K e$-oe plants appeared to be more sensitive to the heat shock than their corresponding wild-type plants (Figure 4). The transgenic plants showed lower survival rates compared to wild-type plants. These results further suggest that $R K e$ orthologs influence rice response to temperature.

The kinase domain of Xa3/Xa26 could replace the kinase domain of NRKe for promoting lesion mimics

NRKe putatively encodes a receptor kinase-type protein consisting of two domains, a LRR domain and a kinase domain, which are connected by a transmembrane motif. Usually, the two domains function together in a complicated way in signal transduction. One exception is rice XA21D, which is a truncated form of the LRR receptor kinase XA21 conferring resistance to Xoo. XA21D has only the LRR domain of XA21, but functions similarly as XA21 in rice-Xoo interactions [26]. To analyze the relationship of different domains of NRKe, two truncated NRKe fragments were, respectively, overexpressed in rice variety Mudanjiang 8 . One truncated NRKe was NRKe$\Delta K$, which encoded protein did not have the kinase domain of NRKe; another truncated NRKe was NRKe-K, which only encoded the kinase domain of NRKe (Figure $5 \mathrm{a})$. Eighteen and 18 independent transformants transformed with $N R K e-\Delta K$ and $N R K e-K$, and named NRKe$\Delta K$-oe and $N R K e-K$-oe, were obtained, respectively. In the same environment, NRKe-oe plants developed marked lesion mimics on their leaves, but $N R K e-\Delta K$-oe and NRKe-K-oe plants were free of lesions (Figure $5 \mathrm{~b}$ ). These results suggest that a complete NRKe is important for the development of lesion mimics.

NRKe is the paralog of the $R$ gene Xa3/Xa26 that confers race-specific resistance against Xoo in rice [6]. The predicted LRR and kinase domains of NRKe and Xa3/ Xa 26 proteins share $68 \%$ and $85 \%$ sequence identity, 


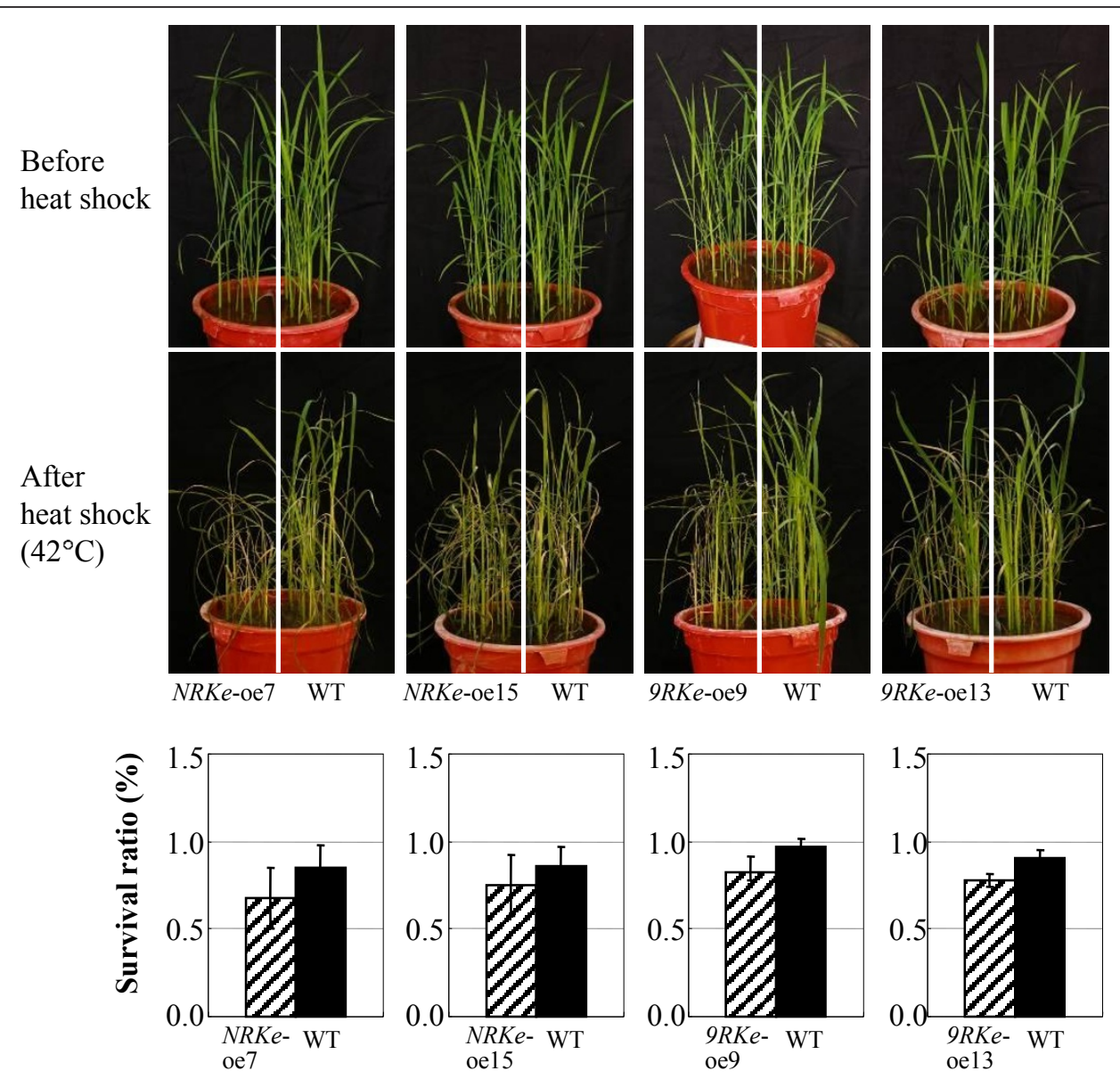

Figure 4 Activation of NRKe or $9 R K e$ caused rice to be more sensitive to increased temperature. NRKe-oe and $9 R K e-0 e$ were $T_{2}$ plants at 4- to 5-leaf stage. WT, wild-type Mudanjiang 8. Bars represent mean (2 technical replicates with each replicate contained 16-20 plants) \pm standard deviation.

respectively (Additional file 1, Figure S4). To determine whether the LRR or kinase domain was critical for the development of lesion mimics, we constructed two chimeric genes, the $B e 1$ and $B e 2$, using the different fragments of NRKe and Xa3/Xa26, and constitutively overexpressed them in rice variety Mudanjiang 8 . The $\mathrm{Be} 1$ consists of the sequences encoding the region in front of LRR, LRR, juxtamembrane region, and transmembrane region of $\mathrm{Xa} 3 / \mathrm{Xa} 26$ and the sequence encoding the kinase domain of NRKe; the $B e 2$ consists of the sequence encoding the region in front of LRR, LRR, juxtamembrane region, and transmembrane region of NRKe and the sequence encoding the kinase domain of Xa3/Xa26 (Figure 6a).

Eleven and 13 independent transformants transformed with $B e 1$ and $B e 2$, and named $B e 1$-oe and $B e 2$-oe, were obtained, respectively. All the Be1-oe plants were free of lesions as the wild-type control plants, but 8 of the 13 $B e 2$-oe plants developed lesion mimics on their leaves at the booting stage (Figure $6 \mathrm{~b}$ ). To determine whether the development of lesion mimics was due to overexpressed $B e 2$, two $\mathrm{T}_{1}$ families (Be2-oe2 and Be2-oe9) derived from two of the $\mathrm{T}_{0}$ plants that developed lesion mimics were further examined for their phenotypes and the existence of $\mathrm{Be} 2$ construct. The development of lesion mimics cosegregated with existence of $\mathrm{Be} 2$ in the two families (Figure $6 c$ ). These results suggest that the kinase domain of Xa3/ Xa26 can replace the kinase domain of NRKe to induce formation of lesion mimics.

Because $\mathrm{Xa3} / \mathrm{Xa} 26$ mediates rice resistance against $X o o$, the $\mathrm{T}_{0} B e 1$-oe and $B e 2$-oe plants were analyzed for their response to Xoo. Most of the $\mathrm{T}_{0} \mathrm{Be1}$-oe and Be2-oe plants were susceptible to Xoo strain PXO61 as the wild type. Two Be1-oe $\mathrm{T}_{1}$ families and two $B e 2$-oe $\mathrm{T}_{1}$ families were further inoculated with PXO61. No increased resistance or susceptibility was associated with the existence of $\mathrm{Be} 1$-oe or $\mathrm{Be} 2$-oe construct in these $\mathrm{T}_{1}$ families (Additional file 1, Figure S5). These results suggest that the kinase domain of NRKe cannot replace the functions of the $\mathrm{Xa} 3 / \mathrm{Xa} 26$ kinase domain in disease resistance. 
$\mathbf{a}$

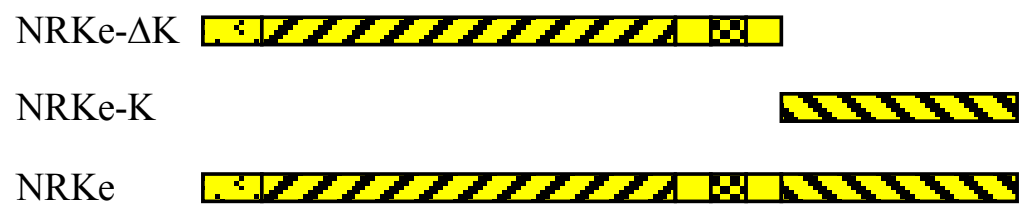

$\square$ LRR
$\square$ Kinase domain
$\square$ Region in front of LRR

b

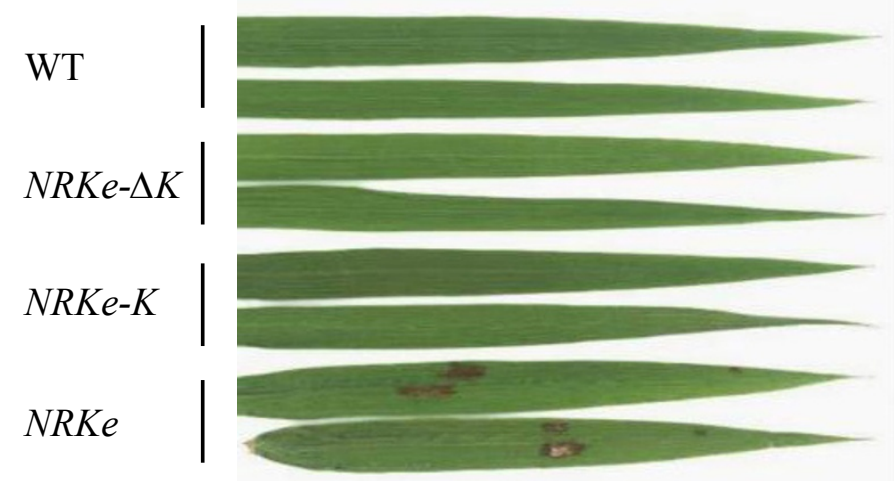

Figure 5 Constitutive expression of truncated $N R K e$, the $N R K e-\Delta K$ and $N R K e-K$ in rice. (a) Predicted protein structures encoded by NRKe, NRKe- $\Delta K$, and NRKe-K. (b) Leaves of transgenic plants overexpressing NRKe- $\triangle K$ (NRKe- $\triangle K$-oe8, To generation), NRKe-K (NRKe-K-oe2, $T_{0}$ generation), or NRKe (NRKe-oe15, T1 generation) at booting stage. WT, wild-type Mudanjiang 8.

\section{Discussion}

The LRR receptor kinase-like plasma membrane proteins are the largest class of receptor-like kinases in plants and this class of proteins are well-known components in signal transduction during different physiologic activities [27]. For example, the CLAVATA1 regulates stem cell maintenance and differentiation in Arabidopsis [28]. BRI1 participates in the regulation of Arabidopsis growth and development via brassinosteroid signaling [29]. Rice Xa3/Xa26 and XA21 mediate race-specific and major disease resistance to Xoo $[5,6]$. The RPK1 functions in the abscisic acid signaling pathway related to germination, growth, and stomatal closure in Arabidopsis [30]. ERECTA specifies the size and shape of mature organs in Arabidopsis [31]. A LRR receptor kinase-like gene may be associated with the resistance to Heterodera glycines in soybean and the resistance to $H$. glycines is temperature sensitive $[32,33]$. The results presented here add another example that this type of protein, rice NRKe and 9RKe, appears to be involved in rice response to increased temperature. This inference is supported by the following evidences. First, both NRKe and $9 R K e$ were transcriptionally induced by higher temperature compared to control. Second, activation of this pair of orthologs resulted in rice more sensitive to high temperature.

\section{The LRR domain of RKe is critical to sense increased temperature}

As receptor, the extracellular localized LRR domain of LRR receptor kinase-like protein functions to recognize and bind ligand, which includes proteins, peptides, or nonprotein components, in signal transduction [7]. For example, the LRR domain of BRI1 mediates brassinosteroid signaling by interacting with brassinolide, the active form of brassinosteroids [34]. Arabidopsis FLS2-mediated immunity is initiated by binding a bacterial flagellinderived peptide Flg22 to its LRR domain [35]. Rice Xa21regulated race-specific disease resistance is triggered by binding a sulfated peptide secreted by Xoo to its LRR domain [36]. Constitutive expression of the orthologs in the $R K e$ locus resulted in the formation of lesion mimics, which was related to increased temperature (Figure 2). Thus, the appearance of lesion mimics in the NRKe- or $9 R K e$-transgenic plants is a marker of rice response to raised temperature through $N R K e$ - or $9 R K e$-initiated signaling, although the appearance of lesion mimics did not 
a

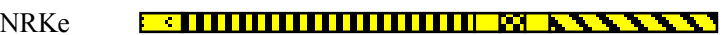 \\ $\mathrm{Xa} 3 / \mathrm{Xa} 26$ \\ $\mathrm{Be} 1$ \\ $\mathrm{Be} 2$}

b

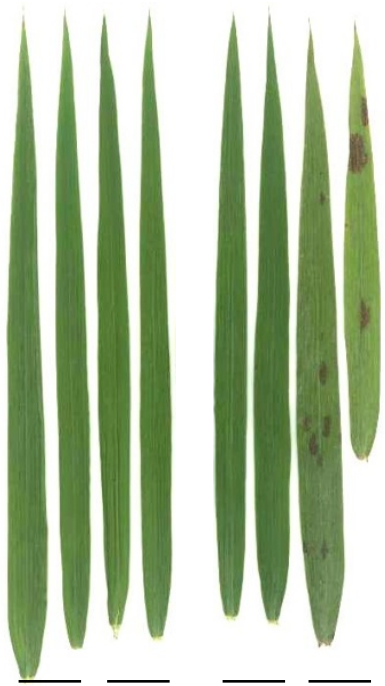

Xa3/Xa26 (782) NTSAGKADLISHQLLSYHELLRATDDFSDDSMLGFGSFGKVFRGRLSNGM (831)

NRKE (772) ENPADMVDTINHQLLSYNELAHATNDFSDDNMLGSGSFGKVFKGQLSSGL (821)

BE1 (782) NTSAGKADLISHQLLSYHELLRATDDFSDDNMLGSGSFGKVFKGQLSSGL (831)

BE2 (772) ENPADMVDTINHQLLSYNELAHATNDFSDDSMLGFGSFGKVFRGRLSNGM (821)
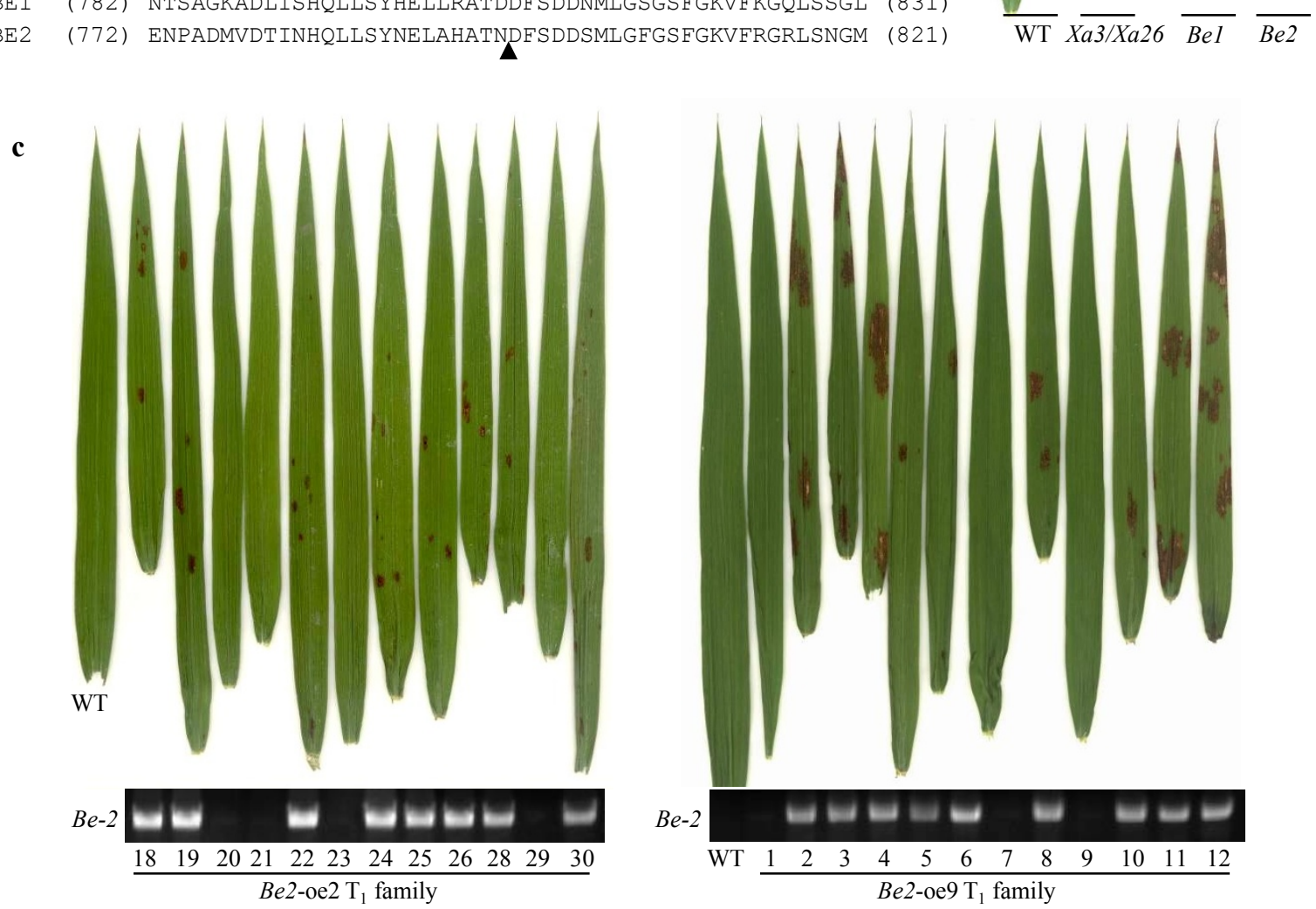

Figure 6 The chimeric proteins and phenotypes of transgenic plants overexpressing chimeric gene. (a) Schematic diagram of the proteins encoded by the chimeric genes $\mathrm{Be} 1$ and $\mathrm{Be} 2$ and the sequences around the fusion sites. Arrowhead indicates the fusion sites in Be1 and Be2 proteins. (b) Leaves of transgenic plants overexpressing Xa3/Xa26 (MKbFMDJ2 line)[12], Bel (Be1-oe1, To generation), or Be2 (Be2-oe2, To generation) in the same genetic background. WT, wild-type Mudanjiang 8. (c) Formation of lesion mimics on the leaves cosegregated with the existence of $B e 2$ in two $T_{1}$ families at booting stage.

represent a physiologic condition. The lesion mimic or lesion mimic-free phenotypes of different chimeric genecarrying plants suggest that the LRR domain of the RKe protein is essential for the induction of lesion mimics (Figure 6). These results in turn indicate that formation of lesion mimics may be associated with the binding of temperature-associated ligand to the LRR domain.

Spontaneous formation of lesion mimics in the leaves of NRKe-, 9RKe-, and Be2-transgenic plants cultured in sterilized containers was observed during tissue culture, 
which suggests that the ligand bound to the LRR domains of NRKe and 9RKe to induce the formation of temperature-sensitive lesion mimics was not from the changed environment. Thus, we argue that the ligand may be originated in rice. When the temperature rises, the ligand appears or its concentration is increased and RKe interacts with the ligand to trigger downstream reaction. However, further study is required to examine this hypothesis.

\section{The downstream pathways of RKe and Xa3/Xa26 may partially overlap}

The intracellular localized kinase domain of LRR receptor kinase is the performer of transduction of the signal recognized by the LRR domain [7]. A previous report has revealed that a complete LRR receptor kinase-like protein including both the LRR and kinase domains in the Xa3/ $\mathrm{Xa} 26$ family is important for conferring disease resistance; the kinase domain of a paralog in this family can partially replace the function of the kinase domain of resistance protein Xa3/Xa26 in response to Xoo [13]. Consistent with this previous report, our present results show that neither activation of the truncated NRKe lacking the kinase domain (NRKe- $\Delta \mathrm{K})$ nor activation of the kinase domain of NRKe (NRKe-K) can promote the formation of lesion mimics. The kinase domain of Xa3/Xa26 (in the case of $\mathrm{Be} 2$ ) can restore the function of $\mathrm{NRKe}-\Delta \mathrm{K}$ in promoting the formation of lesion mimics. However, the kinase domain of NRKe could not replace the kinase domain of $\mathrm{Xa} 3 / \mathrm{Xa} 26$ (in the case of Be1) for Xoo resistance. These results suggest that the kinase domain of Xa3/Xa26 could afford all the functions of kinase domain of NRKe in formation of lesion mimics, but the latter could not provide the function of the former in disease resistance. Thus, some components of the downstream pathways of NRKe and Xa3/Xa26 may be shared.

The above inference is also supported by the fact that NRKe and $\mathrm{Xa3} / \mathrm{Xa} 26$ belong to a tandem clustered $R$ gene family; some amino acid sites of LRR domains encoded by the genes in this family are subject to positive selection, whereas the kinase domains encoded by these genes are evolutionarily conserved, suggesting the functional constraint of the kinase domains in this family [9]. However, not all the paralogs in this family possess the ability to confer disease resistance, although they have a similar tissue-specific expression pattern $[11,13]$. The present results suggest that some paralogs of the $R$ gene family may be involved in other biological processes, like NRKe and 9RKe.

\section{Conclusion}

The tandem repeated paralogs of a haplotype and their orthologs in different haplotypes of $R$ gene family provide different resistance specificities and a sequence reservoir for evolutionary forces to rapidly generate new $R$ genes [37]. A previous report revealed that one paralog of tomato $R$ gene Pto family, the Fen, confers sensitivity to fenthion, an organophosphorous insecticide [38]. Our results further suggest that the "defeated" $R$ genes, like NRKe and $9 R K e$, can also be involved in responses to raised temperature in rice, in addition to serving as the structural reservoir for creating new genes.

\section{Additional material}

Additional file 1: Supplemental table and figures. Table S1: $P C R$ primers used for plasmid construction and gene expression analysis. Figure S1: Expression of NRKe and 9RKe in transgenic plants (To generation) analyzed by RNA gel blot. NRKe-oe, NRKe-overexpressing plants; 9KRe-oe, 9RKe-overexpressing plants; WT, wild-type Mudanjiang 8. Figure S2: NRKe-overexpressing and Be2-overexpressing plants formed lesion mimics spontaneously in sterilized container during tissue culture. Figure S3: Alignment of promoter regions of NRKe and 9RKe. The nucleotides immediately upstream of the translation start codon ATG are numbered as "-1". The putative heat-responsive cis-elements are underlined. HSE (nGAAn core), heat shock element consisting of repeated core nGAAn in alternate orientation; HSE (PlantCARE), heat shock element found in PlantCARE database; CCAAT box (Place), CCAAT box found in PLACE database. Figure S4: Alignment of kinase domains of NRKe and Xa3/Xa26. The solid black shade indicates different amino acid residues and the gray shade indicates residues with similarity. Asterisks $\left(^{*}\right)$ indicate conserved amino acid residues of protein kinase (Hanks SK et al. Science 1998, 241:42-52). The conserved subdomains are numbered and underlined according to Cao et al. (Cao Y et al. Theor Appl Genet 2007, 115:887-895). Figure S5: Overexpression of Be1 or Be2 could not influence rice response to $X_{00}$ strain $P X O 61$. Positive transgenic plants were determined by PCR amplification of Bel or Be2 using gene-specific primers (Additional file 1, Table S1). Wild type (WT) is Mudanjiang 8. Rb49 is a transgenic line carrying $\mathrm{Xa3} / \mathrm{Xa26}$ driven by its native promoter in Mudanjiang 8 background.

\section{Acknowledgements}

This work was supported by grants from the National Natural Science Foundation of China (30930063, 30921091).

\section{Authors' contributions}

$\mathrm{HZ}$ performed functional complementation and gene expression analyses and drafted the manuscript. YC and JZ provided biochemical and transgenetic technical support. XL and JX provided molecular analysis support. SW contributed to data interpretation and to writing the manuscript. All authors read and approved the final manuscript.

Received: 30 June 2011 Accepted: 15 November 2011 Published: 15 November 2011

\section{References}

1. Dangl $J$, Jones JD: Plant pathogens and integrated defence responses to infection. Nature 2001, 411:826-833.

2. Eitas TK, Dangl JL: NB-LRR proteins: pairs, pieces, perception, partners, and pathways. Curr Opin Plant Biol 2010, 13:472-477.

3. Liu J, Wang X, Mitchell T, Hu Y, Liu X, Dai L, Wang GL: Recent progress and understanding of the molecular mechanisms of the riceMagnaporthe oryzae interaction. Mol Plant Pathol 2010, 11:419-427.

4. Kruijt M, MJ DEK, de Wit PJ: Receptor-like proteins involved in plant disease resistance. Mol Plant Pathol 2005, 6:85-97.

5. Song WY, Wang GL, Chen LL, Kim HS, Pi LY, Holsten T, Gardner J, Wang B, Zhai $W X$, Zhu LH, Fauquet $C$, Ronald $P$ : A receptor kinase-like protein encoded by the rice disease resistance gene, Xa21. Science 1995, 270:1804-1806. 
6. Sun X, Cao Y, Yang Z, Xu C, Li X, Wang S, Zhang Q: Xa26, a gene conferring resistance to Xanthomonas oryzae pv. oryzae in rice, encodes an LRR receptor kinase-like protein. Plant J 2004, 37:517-527.

7. Torii KU: Leucine-rich repeat receptor kinases in plants: structure, function, and signal transduction pathways. Int Rev Cytol 2004, 234:1-46.

8. Yang Z, Sun X, Wang S, Zhang Q: Genetic and physical mapping of a new gene for bacterial blight resistance in rice. Theor Appl Genet 2003, 106:1467-1472.

9. Sun $X$, Cao $Y$, Wang S: Point mutations with positive selection were a major force during the evolution of a receptor-kinase resistance gene family of rice. Plant Physiol 2006, 140:998-1008.

10. $X u$ S, Cao Y, Li X: Expressional and biochemical characterization of rice disease resistance gene Xa3/Xa26 family. J Integr Plant Biol 2007, 49:852-862.

11. Xu L, Li X, Wang S: Analysis on expression patterns of the family members of rice bacterial blight resistance gene $\mathrm{Xa3} / \mathrm{Xa26}$. Chinese J Rice Sci 2008, 22:559-563.

12. Cao $Y$, Duan $L$, Li H, Sun $X$, Zhao $Y, X u$ C, Li X, Wang S: Functional analysis of Xa3/Xa26 family members in rice resistance to Xanthomonas oryzae pv. oryzae. Theor Appl Genet 2007, 115:887-895.

13. Cao $Y$, Ding $X$, Cai M, Zhao J, Lin Y, Li X, Xu C, Wang S: The expression pattern of a rice disease resistance gene $\mathrm{X} a 3 / \mathrm{Xa26}$ is differentially regulated by the genetic backgrounds and developmental stages that influence its function. Genetics 2007, 177:523-533.

14. Gao J, Zhao J, Xu C, Li X, Wang S: Development of rice germplasms conferring high-level and broad-spectrum resistance to Xanthomonas oryzae pv. oryzae at both seedling and adult stages. Mol Plant Breeding 2010, 8:420-425.

15. Li H, Li X, Xiao J, Wing RA, Wang S: Ortholog alleles at Xa3/Xa26 locus confer conserved race-specific resistance against Xanthomonas oryzae in rice. Molecular Plant 2011.

16. Zhao J, Fu J, Li X, Xu C, Wang S: Dissection of the factors affecting development-controlled and race-specific disease resistance conferred by leucine-rich repeat receptor kinase-type $R$ genes in rice. Theor Appl Genet 2009, 119:231-239

17. Lin $Y$, Zhang Q: Optimising the tissue culture conditions for high efficiency transformation of indica rice. Plant Cell Rep 2005, 23:540-547.

18. Chen $\mathrm{H}$, Wang S, Zhang Q: New gene for bacterial blight resistance in rice located on chromosome 12 identified from Minghui 63, an elite restorer line. Phytopathology 2002, 92:750-754.

19. Chu Z, Ouyang Y, Zhang J, Yang H, Wang S: Genome-wide analysis of defense-responsive genes in bacterial blight resistance of rice mediated by the recessive $R$ gene xa13. Mol Genet Genomics 2004, 271:111-120.

20. Qiu D, Xiao J, Ding X, Xiong M, Cai M, Cao Y, Li X, Xu C, Wang S: OsWRKY13 mediates rice disease resistance by regulating defenserelated genes in salicylate- and jasmonate-dependent signaling. $\mathrm{Mol}$ Plant Microbe Interact 2007, 20:492-499.

21. Yuan B, Shen X, Li X, Xu C, Wang S: Mitogen-activated protein kinase OsMPK6 negatively regulates rice disease resistance to bacterial pathogens. Planta 2007, 226:953-960.

22. Jung YH, Lee JH, Agrawal GK, Rakwal R, Kim JA, Shim JK, Lee SK, Jeon JS, Koh HJ, Lee YH, Iwahashi H, Jwa NS: The rice (Oryza sativa) blast lesion mimic mutant, blm, may confer resistance to blast pathogens by triggering multiple defense-associated signaling pathways. Plant Physiol Biochem 2005, 43:397-406.

23. Yang Y, Qi M, Mei C: Endogenous salicylic acid protects rice plants from oxidative damage caused by aging as well as biotic and abiotic stress. Plant J 2004, 40:909-919.

24. Amin J, Ananthan J, Voellmy R: Key features of heat shock regulatory elements. Mol Cell Biol 1988, 8:3761-3769.

25. Haralampidis K, Milioni D, Rigas S, Hatzopoulos P: Combinatorial interaction of cis elements specifies the expression of the Arabidopsis AtHsp90-1 gene. Plant Physiol 2002, 129:1138-1149.

26. Wang GL, Ruan DL, Song WY, Sideris S, Chen L, Pi LY, Zhang S, Zhang Z, Fauquet C, Gaut BS, Whalen MC, Ronald PC: Xa21D encodes a receptorlike molecule with a leucine-rich repeat domain that determines racespecific recognition and is subject to adaptive evolution. Plant Cell 1998, 10:765-779.

27. Dievart A, Clark SE: LRR-containing receptors regulating plant development and defense. Development 2004, 131:251-261.
28. Clark SE, Williams RW, Meyerowitz EM: The CLAVATA1 gene encodes a putative receptor kinase that controls shoot and floral meristem size in Arabidopsis. Cell 1997, 89:575-585.

29. Li J, Chory J: A putative leucine-rich repeat receptor kinase involved in brassinosteroid signal transduction. Cell 1997, 90:929-938.

30. Osakabe Y, Maruyama K, Seki M, Satou M, Shinozaki K, YamaguchiShinozaki K: Leucine-rich repeat receptor-like kinase1 is a key membrane-bound regulator of abscisic acid early signaling in Arabidopsis. Plant Cell 2005, 17:1105-1119.

31. Torii KU, Mitsukawa N, Oosumi T, Matsuura Y, Yokoyama R, Whittier RF, Komeda Y: The Arabidopsis ERECTA gene encodes a putative receptor protein kinase with extracellular leucine-rich repeats. Plant Cell 1996, 8:735-746.

32. Palmateer AJ, Schmidt ME, Stetina SR, Russin JS: Temperature Effects on Race Determination in Heterodera glycines. J Nematol 2000, 32:349-355.

33. Ruben E, Jamai A, Afzal J, Njiti VN, Triwitayakorn K, labal MJ, Yaegashi S, Bashir R, Kazi S, Arelli P, Town CD, Ishihara H, Meksem K, Lightfoot DA: Genomic analysis of the rhg1 locus: candidate genes that underlie soybean resistance to the cyst nematode. Mol Genet Genomics 2006, 276:503-516.

34. Kinoshita T, Cano-Delgado A, Seto H, Hiranuma S, Fujioka S, Yoshida S, Chory J: Binding of brassinosteroids to the extracellular domain of plant receptor kinase BRI1. Nature 2005, 433:167-171.

35. Chinchilla D, Bauer Z, Regenass M, Boller T, Felix G: The Arabidopsis receptor kinase FLS2 binds flg22 and determines the specificity of flagellin perception. Plant Cell 2006, 18:465-476.

36. Lee SW, Han SW, Sririyanum M, Park CJ, Seo YS, Ronald PC: A type Isecreted, sulfated peptide triggers XA21-mediated innate immunity. Science 2009, 326:850-853.

37. Michelmore RW, Meyers BC: Clusters of resistance genes in plants evolve by divergent selection and a birth-and-death process. Genome Res 1998, 8:1113-1130

38. Martin GB, Frary A, Wu T, Brommonschenkel S, Chunwongse J, Earle ED, Tanksley SD: A member of the tomato Pto gene family confers sensitivity to fenthion resulting in rapid cell death. Plant Cell 1994, 6:1543-1552.

doi:10.1186/1471-2229-11-160

Cite this article as: Zhang et al:: A pair of orthologs of a leucine-rich repeat receptor kinase-like disease resistance gene family regulates rice response to raised temperature. BMC Plant Biology 2011 11:160.

\section{Submit your next manuscript to BioMed Central and take full advantage of:}

- Convenient online submission

- Thorough peer review

- No space constraints or color figure charges

- Immediate publication on acceptance

- Inclusion in PubMed, CAS, Scopus and Google Scholar

- Research which is freely available for redistribution

Submit your manuscript at www.biomedcentral.com/submit
C Biomed Central 